\title{
Aplicación del conocimiento ancestral mediante albarradas y tapes en la gestión del agua en la provincia de Santa Elena, Ecuador
}

\author{
Gricelda Herrera-Franco(1), Paúl Carrión-Mero(2) y Josué Briones-Bitar ${ }^{(2)}$ \\ (1) Universidad Estatal Península de Santa Elena, UPSE, Facultad de Ciencias de la Ingeniería, \\ Av. Principal Santa Elena-La Libertad, Ecuador. \\ grisherrera@upse.edu.ec \\ (2) Escuela Superior Politécnica del Litoral, ESPOL, Centro de Investigaciones y Proyectos Aplicados a las Ciencias de la Tierra (CIPAT), \\ Facultad de Ingeniería en Ciencias de la Tierra (FICT), \\ Campus Gustavo Galindo Km 30.5 Vía Perimetral, P.O. Box 09-01-5863, Guayaquil, Ecuador. \\ pcarrión@espol.edu.ec; briones@espol.edu.ec
}

RESUMEN

La gestión integral del agua es relevante para la sostenibilidad mediante la aplicación de criterios de acumulación, recarga y control ambiental de una cuenca hidrográfica, potenciados por el rescate del conocimiento ancestral. En la provincia de Santa Elena (PSE), datan cientos de estructuras de albarradas y tapes, construidos por culturas precolombinas para la gestión del agua. El objetivo de este trabajo es presentar la práctica del conocimiento ancestral ligado al agua subterránea mediante la descripción del uso de albarradas y tapes para la provisión de agua en comunidades rurales en terrenos semiáridos. La metodología desarrollada contempla: i) generalidades sobre el uso de estructuras de tipo ancestral; ii) descripción de las albarradas y tapes en PSE; iii) esquema de la estructura de estos conocimientos ancestrales; iv) rescate y práctica para la gestión del agua, en sectores semiáridos. En PSE existen vestigios de albarradas y tapes en el área rural, que delatan una historia y experiencias en la gestión y aprovechamiento del agua subterránea en sus territorios. El gobierno ecuatoriano ha respaldado el rescate del conocimiento mediante la rehabilitación de las albarradas. En Manglaralto, la propia comunidad, con aliados estratégicos, han ido evolucionando y adaptando estos conocimientos ancestrales, para responder a una demanda creciente, y así proveer de agua a su propia comunidad, fortaleciendo sus actividades productivas como turismo y agricultura. Actualmente, mediante albarradas y tapes se han llevado a la práctica un sistema de siembra y cosecha de agua (SyCA) que se convierte en clave para la sostenibilidad del agua y desarrollo de las comunidades rurales.

Palabras clave: acuífero, agua subterránea, conocimiento ancestral, recarga, sostenibilidad.

\section{Ancestral knowledge application via" albarradas" and" tapes" in water management in Santa Elena province, Ecuador}

\begin{abstract}
Integral water management is relevant for sustainability through the criteria application of accumulation, recharge and environmental control of a watershed, enhanced by the rescue of ancestral knowledge. In the Santa Elena province (PSE), there are hundreds of structures of "albarradas" and "tapes", built by pre-Columbian cultures as tools for water management. The aim of this paper is to present ancestral knowledge linked to groundwater by describing the use of "albarradas" and "tapes", for the provision of water in rural communities in semi-arid areas. The methodology includes: i) generalities on the use of ancestral structures; ii) description of the "albarradas" and "tapes" in the PSE; iii) conceptual scheme of the structure of this ancestral knowledge; iv) rescue and practice for water management in semiarid areas. In the PSE there are vestiges of more than a hundred "albarradas" and "tapes" in rural areas, which reveal a history and experiences in the management and use of groundwater in these territories. The Ecuadorian government has supported the rescue of knowledge through the rehabilitation of the "albarradas". In Manglaralto, the community itself, together with strategic allies, has been evolving and adapting this ancestral knowledge, to respond to a growing demand, and thus provide water for their own community, and they have been strengthening their productive activities such as tourism and agriculture. Nowadays, by using the "albarradas" and "tapes", a system of planting and harvesting water has been put into practice (SyCA), and has becomes the key for water sustainability and the development of rural communities.
\end{abstract}

Keywords: ancestral knowledge, aquifer, groundwater, recharge, sustainability. 


\section{Introducción}

El panorama sobre la situación de suministro y renovación del agua en el mundo es cada día peor; ya que, el agua dulce disponible no está equitativamente distribuida en el mundo, ni en la misma cantidad en las estaciones; varía de un año a otro (Agudelo, 2005); por lo que, las aguas dulces, de todo el mundo, constituyen un recurso escaso, amenazado y en peligro. Por eso, es fundamental considerar una integralidad en la gestión del agua para contrarrestar la carencia de la misma (Sixt et al. 2018). El recurso agua se plantea como un activo social (Kosolapova et al. 2017), en el sentido específico de que pertenece a la sociedad, facilitando un estilo de vida determinado, formando parte fundamental de la riqueza de un país y proporcionando un conjunto de funciones ambientales que permiten el mantenimiento de la vida (Marcos and Tobar, 2004). Ya que se trata de un recurso necesario para la vida; el abastecimiento, el saneamiento y la buena gestión del agua son elementos prioritarios en el sector social y por ende importantes para preservar el medio ambiente y la lucha contra la pobreza (Herrera and Flores, 2011).

El agua es una propiedad y un recurso común, y en algunos casos es considerado como un patrimonio común, lo que involucra la gestión colectiva del recurso natural, e implica otorgar a una institución comunitaria la capacidad de gestionar y transmitir a lo largo del tiempo los recursos que son los símbolos y los medios de existencia de la comunidad (Calvo-Mendieta et al. 2017). Muchos han argumentado que las comunidades locales deben participar en la gestión del entorno en general (Gunderson and Holling, 1995). La gestión sostenible de los recursos naturales no puede lograrse sin la participación de las comunidades afectadas. Es necesario superar las concepciones tradicionales de desarrollo, donde las comunidades participaban como mano de obra, para disminuir costos. La participación comunitaria se debe dar en el analizar, el hacery el decidir (Schwartz and Deruyttere, 1996).

La Provincia de Santa Elena (PSE), en Ecuador, a causa de la deforestación sufrida históricamente desde 1990 se transformó en un área con gran déficit de recursos hídricos, donde la desertificación avanza paulatinamente (EI Universo, 2012). La escasez de agua se registra desde hace más de 100 años, lo cual obedece principalmente a la tala indiscriminada evidenciando una disminución en la cobertura vegetal de las cuencas y micro cuencas, lo cual ha provocado procesos de erosión intensos (Rivadeneira and Peralta Proaño, 2009); además, la contaminación de aguas costeras debido a las actividades agrícolas, mineras e industriales, la sobreexplotación de aguas subterrá- neas impulsada por actividades humanas, y el retroceso de los glaciares andinos que alimentan los ríos (Pazmiño Manrique et al. 2018). Esta región, influenciada por la interacción de las corrientes marinas frías del sur (Humboldt) y las cálidas del norte (El Niño), se caracteriza por presentar unas precipitaciones anuales que están por debajo de los $250 \mathrm{~mm}$ anuales (Herrera, 2015) y unos niveles de evapotranspiración cercanos a $1000 \mathrm{~mm}$ anuales (Valencia, 2017), que agrava más aún el problema del abastecimiento y distribución del recurso hídrico para la zona (Saeteros, 2014).

Las comunidades también están a la vanguardia de la lucha contra el cambio climático (Galloway McLean, 2010). Si bien generalmente se los presenta como víctimas de la pobreza y la vulnerabilidad al cambio climático (Arévalo, 2017), también corresponde destacar su sensibilidad hacia el medio ambiente, capacidad de adaptación y resiliencia, características que se ponen de relieve en su capacidad para modificar conductas en respuesta a los cambios que sufre el clima (Nakashima et al. 2012). Los conocimientos de las comunidades pueden contribuir en gran medida a los procesos de observación y mitigación de las consecuencias del cambio climático y de su adaptación a ellas

El rescate de conocimientos ancestrales en la gestión local de agua se evidencia en comunidades latinoamericanas, como el suka kollus, considerado una importante estructura hidráulica de la tecnología andina ancestral en Bolivia, enfocado en la producción de cultivos en suelos propensos a inundaciones permitiendo el riego subsuperficial de los cultivos por medio de canales de drenaje (Erickson, 1992; Ortloff, 1999; Serrano-Coronel et al. 2018). Otra estructura hidráulica ancestral destacada es el sistema de amunas en Perú, éste tiene mayor presencia en la serranía y constituye una práctica ancestral de recarga de acuíferos (Ancajima Ojeda, 2015). Además, existen una gran cantidad de rituales ancestrales para solicitar agua, los cuales son resultados de experiencias vivenciales de miles de años (Yapa, 2013).

En el Ecuador, se han venido desarrollando técnicas ancestrales para el cuidado y la preservación del agua, especialmente en los sectores rurales; donde, es muy difícil que cuenten con agua potable, y se debe buscar otras medidas o alternativas para obtener este importante recurso (Stothert, 1995). En la PSE, datan cientos de estructuras hidráulicas ancestrales tales como albarradas y tapes, construidos por culturas precolombinas como herramienta de la gestión del agua (Marcos y Tobar, 2004). Dada la presencia de largos períodos de sequía en la PSE, la población indígena de la costa ecuatoriana (cholos ecuatorianos) han construido estas estructuras hidráulicas destinadas a la captación y almacenamiento de agua que da soporte a la 
reproducción socio-cultural y ambiental de la región hasta nuestros días (Álvarez Litben and Zulaica, 2015).

Otra estructura hidráulica ancestral destacada es la construcción de sistemas de albarradas, cuyo término tradicional es "jagüey" (Váldez, 2006). Las albarradas, según ESPOL (1999), son humedales lénticos artificiales, utilizados como reservorios de agua. Estos se llenan mediante el proceso de acumulación de agua lluvia en invierno y de los pequeños riachuelos de las cuencas locales, además de favorecer la infiltración, con lo cual se alimentaban los acuíferos de la zona, con el propósito de utilizar el agua durante la temporada seca (Figura 1). También las albarradas han sido consideradas como muros delimitadores de espacios no residenciales asociados a la agricultura, apicultura, ganadería y arboricultura (Paris et al., 2018).

Los tapes o diques artesanales es una denominación que los comuneros, personas que habitan en una comunidad, le han dado a la acumulación de rocas y sedimentos en ciertas partes del cauce del río para tratar de represar el agua y permitir que esta se acumule, evitando el paso del agua al océano; esto con el fin de facilitar la recarga de acuíferos (Figura 1, 2 y 3 ).

Las albarradas son muy comunes en ríos de segundo, tercer o cuarto orden; es decir, no en el cauce principal sino en un ramal. No así los tapes, o técni-

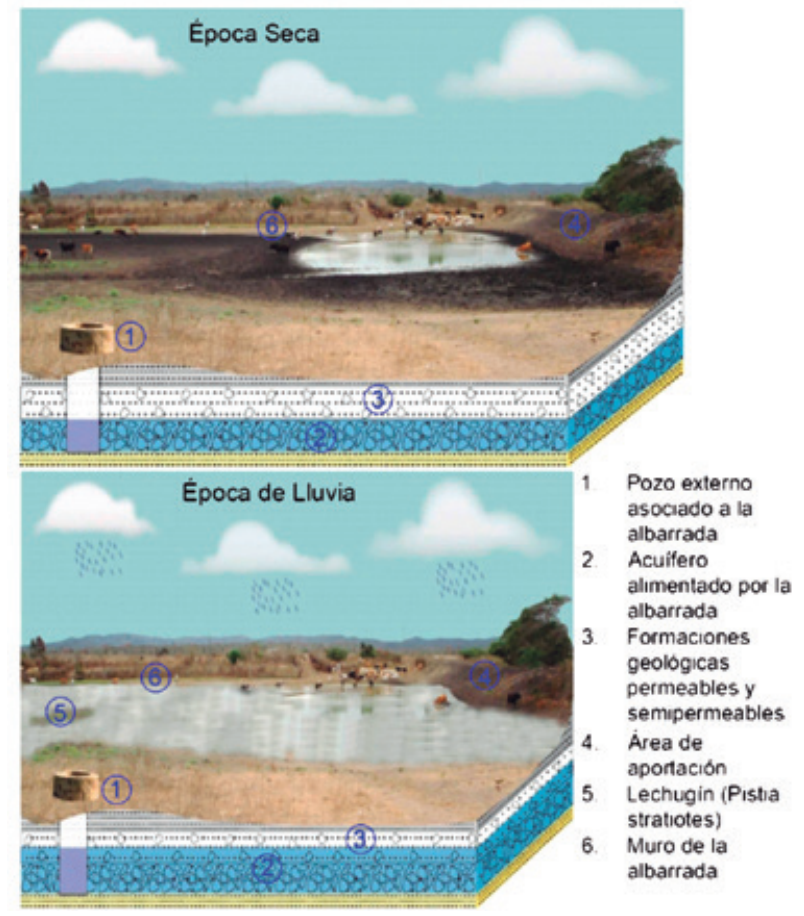

Figura 1. Esquema de una Albarrada (etapa seca y etapa de lluvia). Fuente: Adaptado de Marcos y Tobar, 2004.

Figure 1. Diagram of an "albarrada" (dry and rainy season). Source: Modified from Marcos y Tobar, 2004.

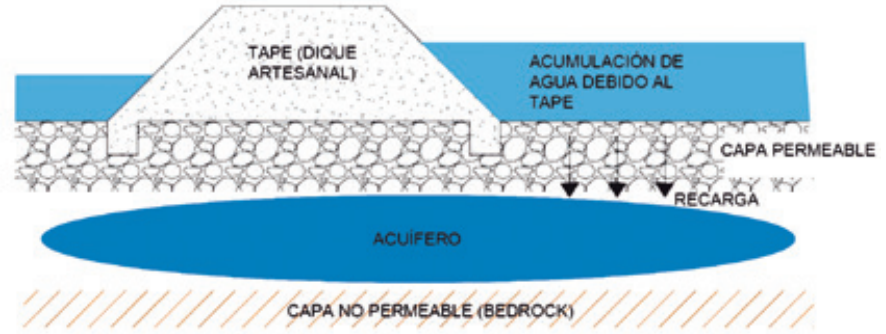

Figura 2. Esquema de un Tape: vista lateral. Fuente: Adaptado de Carrión et al. 2018.

Figure 2. Diagram of a "tape": side view. Source: Modified from Carrión et al. 2018.

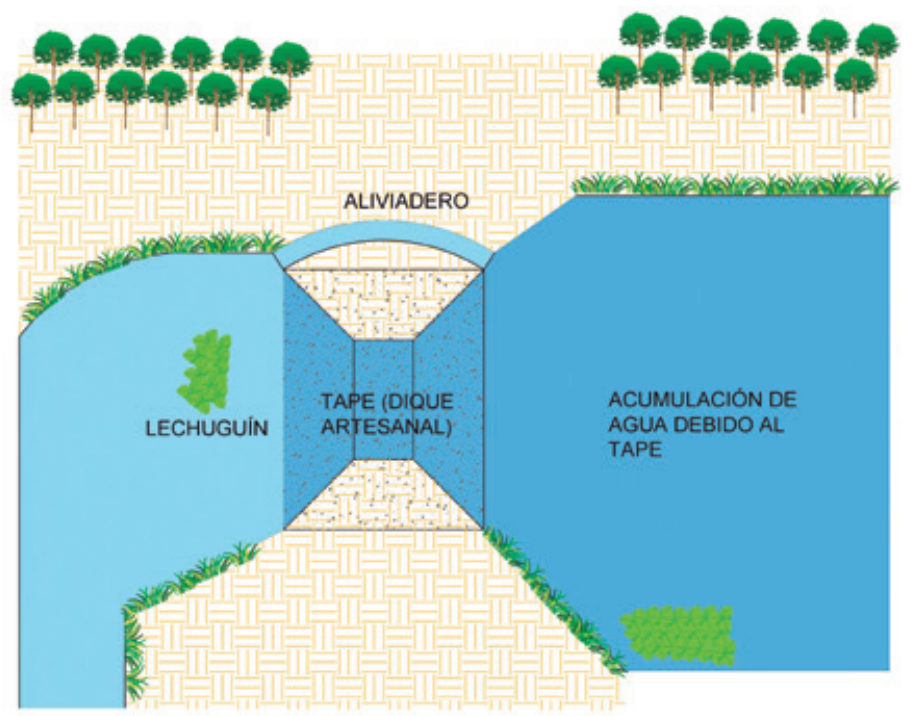

Figura 3. Vista superior del Tape.

Figure 3. Top view of the "tape".

camente llamado dique artesanal, que, al igual que las albarradas, son construidos con un muro de tierra o de hormigón; pero estos son puestos en un cauce principal del río.

En estos sistemas, dependiendo de las precipitaciones, el agua puede permanecer en la superficie, por efectos de las albarradas y los tapes, hasta los meses de septiembre y octubre, dependiendo de las precipitaciones en el periodo de lluvias y la posterior brisa que se da después de julio; $y$, cuando esta se agota, es extraída de los acuíferos a través de pozos, maximizando así su uso. Estos sistemas hidráulicos históricamente han facilitado la obtención de agua fresca y el desarrollo local de las comunidades en la PSE y gran parte de la Costa del Ecuador.

Los sistemas de albarradas, incluyendo pozos de agua, tapes y acuíferos, están íntimamente vinculados con la gobernabilidad sobre el recurso hídrico mediante prácticas locales enfocadas en la sostenibilidad del agua, principalmente en áreas rurales de la cos- 


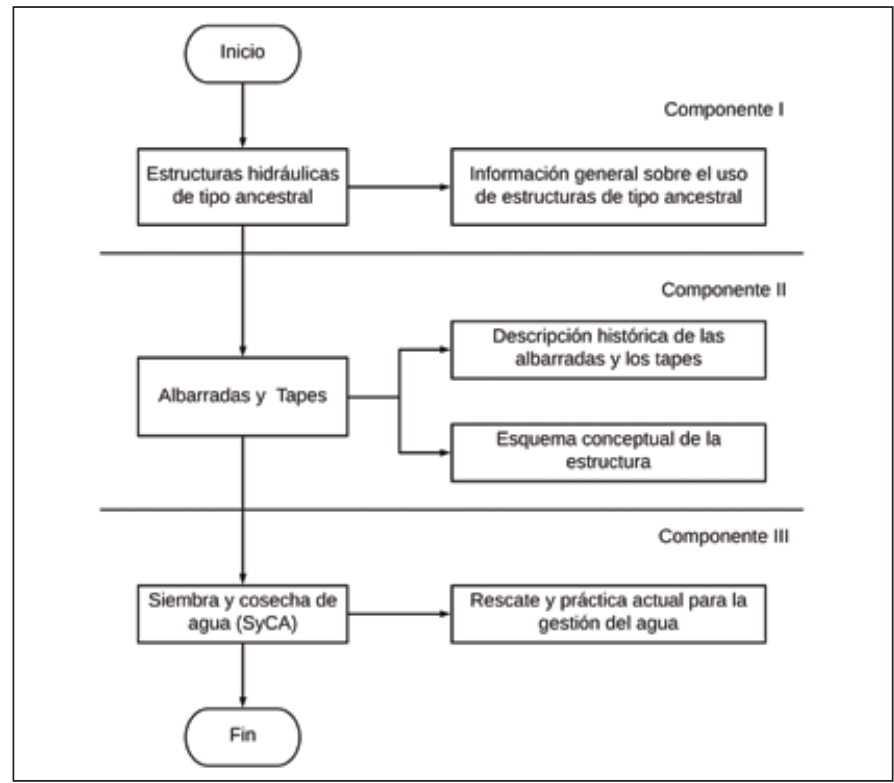

Figura 4. Resumen esquemático de la metodología.

Figure 4. Schematic summary of the methodology.

ta ecuatoriana (Herrera et al. 2018). El conocimiento ancestral incluye técnicas para la sostenibilidad del recurso hídrico, aún usadas en la actualidad, mediante la aplicación de criterios de acumulación, recarga, gestión y control ambiental, principalmente en terrenos semiáridos. El objetivo de este trabajo es presentar la práctica del conocimiento ancestral ligado al agua subterránea mediante la descripción del uso de albarradas y tapes, para la provisión y gestión de agua en comunidades rurales en Santa Elena.

\section{Metodología}

Este trabajo se centra en la PSE, y se encuentra dividido en tres principales componentes, en la que se presenta la práctica del conocimiento ancestral ligado al agua subterránea para la provisión de agua en comunidades rurales en terrenos semiáridos. La metodología se resume esquemáticamente en la Figura 4.

Componente I.- Información general sobre el uso de estructuras de tipo ancestral: Este componente comprende la recopilación de información básica por medio de fuentes o referencias bibliográficas, como artículos, tesis, trabajos e informes de campo que se refiera a este tipo de estructuras ancestrales en el sector de estudio. Una gran fuente de información local sobre conocimiento ancestral se recoge en los libros de Marcos y Tobar (2004) y Álvarez et al. (2004). Mientras que en Yapa (2013) se presenta una recopilación de sistemas de manejo del agua ancestrales en la región de latinoamérica.
Componente II. 1.- Descripción histórica de las albarradas y los tapes en Provincia de Santa Elena. En este apartado se describirá la importancia que tuvieron, y que actualmente tienen, las albarradas y tapes en la PSE. Además, de poner en contexto la cantidad de albarradas y tapes localizados en Ecuador, respecto al número que se han encontrado en la PSE.

Componente II.2.- Esquema conceptual de la estructura de estos conocimientos ancestrales: Esta componente es un complemento de la anterior (II.1), en la que con esquemas se explica el diseño de cada uno de este tipo de estructuras (albarradas y tapes); de cómo, han ido evolucionando en el tiempo y que comunidades, actualmente, las usan para la captación de agua para satisfacer las necesidades de sus habitantes.

Componente III.- Rescate y práctica actual para la gestión del agua (casos de estudio): En esta componente se explicarán algunos casos de estudio como son: i) las 6 albarradas habilitadas por el gobierno del Ecuador en diferentes sectores de la PSE y, ii) el caso particular de la comunidad rural de Manglaralto que, gracias a la ayuda y cooperación con universidades (Universidad Península de Santa Elena/UPSE y Escuela Superior Politécnica del Litoral/ESPOL) ha logrado captar, distribuir y gestionar este recurso de la manera

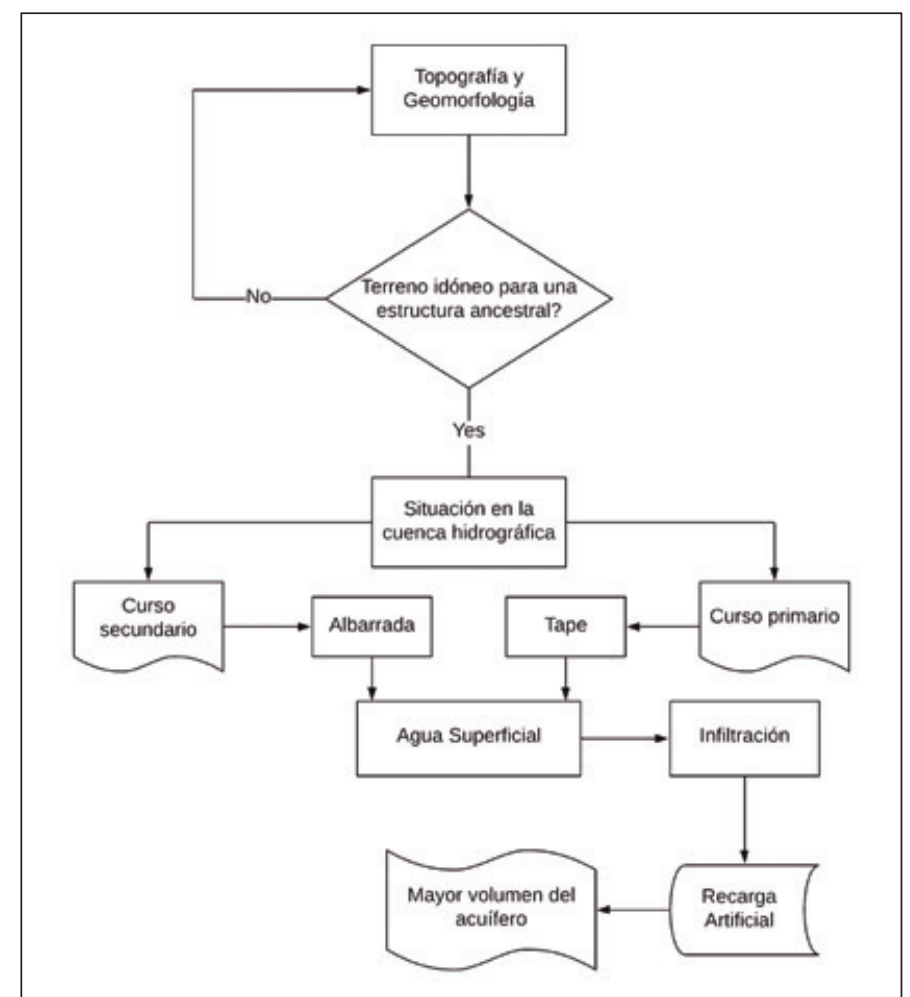

Figura 5. Diagrama del proceso metodológico para las albarradas/tapes.

Figure 5. Diagram of the methodological process of the "albarradas/tapes". 
más efectiva por casi 40 años, ya que la gestión comunitaria del agua en esta cuenca hidrográfica correspondiente al río Manglaralto se inició con la Junta de Agua desde 1979.

Gracias a esta experiencia en Manglaralto, en la Figura 5 se presenta un diagrama de como es el proceso metodológico para las albarradas/tapes que en la práctica se utiliza en el campo.

El diagrama mostrado se puede sintetizar en los siguientes apartados.

i) Inicialmente se basa en la observación mediante recorrido del terreno, considerando todos los aspectos de su relieve, en especial las vías que el agua superficial discurre, notando zonas de infiltración, o simplemente formas superficiales que sirven para represar el agua de una forma sencilla y segura. Normalmente estos lugares tienen la connotación de que naturalmente son propicios para almacenar agua en superficie, por ello los aspectos topográficos y geomorfológicos son extremadamente prioritarios.

ii) Se recorre la cuenca hidrográfica, río arriba o río abajo, hasta llegar a la elección de los lugares más favorables para la ubicación de tapes y/o albarradas. Se deben elegir sitios propicios para un tape o una albarrada, y se valora su utilidad con criterios de observación en el campo.

iii) Los tapes y albarradas se construyen artesanalmente, con el material del río y utilizando el trabajo comunitario de sus miembros. Conceptualmente estos tapes son temporales, ya que en una crecida del río y su creciente cauce puede determinar el fin de su curso. Lo mismo puede ocurrir con las albarradas, aunque normalmente, estas últimas temporalmente son más estables que los tapes.

iv) Al haber agua represada, ya sea por la estructura tape o la albarrada, dependiendo de las condiciones granulométricas del suelo/terreno ocurre la recarga artificial, siendo que al mismo tiempo se dan los procesos de evapotranspiración. El tape y la albarrada dan el servicio de agua superficial y propician la recarga en el acuífero para una futura explotación a través del pozo de agua.

Aquí se ha producido, con el uso de esta metodología, la siembra y cosecha del agua.

\section{Resultados}

\section{Estructuras hidráulicas de tipo ancestral en Santa Elena}

El área se caracteriza por la presencia del Bosque Seco Tropical, en el que se destaca el denominado Centro de EndemismoTumbesino, el cual ha sido reconocido como una zona de gran biodiversidad. Sus cauces son de naturaleza intermitente por no tener una alimen- tación permanente de la cordillera de Los Andes, y por haber perdido un alto porcentaje de su población boscosa, y solo recibe agua cíclicamente del periodo Iluvioso; luego del cual, después de un tiempo el agua se filtra hacia la capa freática en la Formación Tablazo (geológicamente consiste de 4 niveles; primero de lumaquelas y areniscas calcáreas, el segundo caracterizado por la presencia de arenas finas, conglomerados y arcillas, el tercer nivel constituido por arenas de color café, con fragmentos de conchas y el cuarto nivel se encuentra bajo el nivel del mar) y se queda retenida a diferentes profundidades en la Formación Cayo.

Las sociedades precoloniales generaron una cultura particular que las identifica en cuanto a la forma de manejo de los recursos naturales, especialmente hidrológicos, todavía activo y con un alto grado de eficiencia. En zonas áridas, nuestros antepasados se esforzaron mucho para recargar las aguas subterráneas, porque dependían de ellas para vivir. Ante el déficit pronunciado de agua en la zona de la PSE, los habitantes precolombinos desarrollaron algunas obras de ingeniería hidráulica, entre ellas las albarradas. Existen más de un centenar de vestigios de albarradas y tapes en el área rural de la PSE, que delatan una historia y experiencias en la gestión y aprovechamiento del agua subterránea en sus territorios. En Ecuador se han inventariado aproximadamente 800 albarradas, de entre las que 252 se encuentran localizadas en la PSE (Marcos y Tobar, 2004). Estas formaciones facilitan el almacenamiento en un acuífero único, pero sus características hidráulicas relativas, diferenciadas por su propia litología y composición, definen a los sistemas de acuíferos locales dentro del sistema peninsular. En el caso del sistema de albarradas, como en otras formas de transformación de la naturaleza, se evidencian una serie de intenciones orientadas a enriquecer y adaptar el entorno a las necesidades y a las concepciones culturales de la sociedad nativa (Álvarez et al., 2004).

Una de las estructuras asociadas a las albarradas, que ya existían en épocas prehispánicas, eran los pozos entablados, que servían para la extracción del agua del acuífero subyacente. Arqueológicamente se ha podido establecer una relación entre los pozos entablados y albarradas, estos se encuentran localizados en los muros como en la Albarrada de Mealeche en Muey, o en el centro del vaso de las albarradas como en la Albarradas Las Tareas en la frontera entre EnguIlima, Tugaduaja y Chanduy. Además, se evidencian otras actividades asociadas a la cultura indígena en las albarradas, como en el muro de la albarrada de Juan de la Cruz en Muey se hallaron varios entierros en vasijas de barro, con ofrendas de cerámica y otros materiales que datan de entre los años 1690-1730. 
Otra opción de obtención de agua usada por nuestros antepasados fue la neblina. A pesar de recibir muy poca lluvia, casi la mitad del año, la parte norte de la PSE, está bañada con una neblina muy densa y húmeda Ilamada niebla. Estas se forman cuando las corrientes marinas costeras enfrían el aire, y el vapor sobre el mar es empujado hacia la costa; al chocar con el aire frío, se condensa y forma una neblina. Vientos suaves permiten que esta neblina se acumule sobre las lomas bajas y las cubra como una densa manta blanca. Nuestros antepasados lo observaron bien y recogieron el agua atrapada por los árboles en pequeñas pozas excavadas sobre los filos de las lomas. Las pequeñas depresiones como canales recogen las gotas que caen de los árboles a lo largo del filo de las lomas y alimentan las pozas. Este tipo de pozas, de diversas formas y tamaños, se pueden encontrar a lo largo de la costa del Ecuador.

En algunas comunidades decidieron revalorar el aporte de su bosque en atrapar agua de la niebla y lo declararon como reserva, como es el caso de la Reserva Ecológica Comunal de Loma Alta localizada en la Cordillera Chongón-Colonche, esta fue declarado en 1987 con iniciativa de la misma comunidad para proteger las fuentes de agua, evitar invasiones y pérdidas de tierras. El territorio cuenta con mucha riqueza en flora y fauna, además de un vivero y una estación meteorológica. En la actualidad esta es una de las muy pocas lomas costeras ecuatorianas que aún están cubiertas de bosques (Yapa, 2013).

\section{Albarradas y tapes en Santa Elena: Historia y estructura}

En la PSE, en la cuenca del Guayas, o en cualquier otro sector de las zonas rurales de la Costa Ecuatoriana, los nativos sabían, y aún saben cómo obtener agua limpia, aunque no purificada, para satisfacer sus necesidades; sea de un acuífero (pozo), de un ojo de agua (chorrera, chorrillo), o del banco del río (pozo). Las albarradas y tapes fueron la respuesta a los problemas de escasez de agua que enfrentaron las sociedades desde épocas muy tempranas.

\section{Albarradas}

El término albarrada entró en uso en el Ecuador a principios del siglo XX. Sus formas son variadas: circulares, semicirculares (forma de herradura), o circular alargada (con cola). En la mayoría de los casos, las albarradas se encuentran construidas sobre suelos semipermeables, fundamentalmente la Formación Tablazo, lo cual las dota de una de sus más importantes características, la de constituirse en eficientes mecanismos de recarga de los acuíferos.
Es probable que la determinación del sitio óptimo para construir albarradas haya sido la observación de charcas naturales, que se formaban en la planicie interfluvial de una pequeña cuenca, luego de que pasaba la escorrentía de las lluvias tropicales; permitiendo registrar y sistematizar a los pobladores que la mayor parte de esta agua lluvia se perdía al mar, mientras que la que se retenía en la albarrada se filtraba y encharcaba el entorno. La observación frecuente de este fenómeno, llevaría a la población que se nutría de la infrecuente albarrada a tratar de ampliarla para captar una mayor cantidad de agua fresca y conservarla en el substrato geológico. Con el tiempo se dieron cuenta de que no era imprescindible ampliar una albarrada existente, sino que se podía excavar una albarrada artificial (pozo de préstamo o pozo externo asociado a la albarrada) en la parte baja de la planicie interfluvial por donde pasaba la escorrentía. Posteriormente, utilizaban el material extraído por la excavación cerrando con un terraplén a manera de muro de herradura la salida del agua, por lo que la capacidad de captación de la albarrada aumentaba (ESPOL, 1999; Yapa, 2013).

La búsqueda del sitio óptimo produjo que la localización de las albarradas se hiciese donde el reboso natural ocurriese dándose antes de los brazos el muro y no a través de estos o de su cabecera, preservando al muro de ser destruido sin importar cuán fuerte llegase a ser la escorrentía. Con el tiempo, se dieron cuenta de que la escorrentía, al ser detenida en la estructura que habían creado, especialmente al filtrarse el agua hacia las formaciones geológicas subyacentes, se iban sedimentando los suelos arcillo-limosos que arrastraban las aguas (en suspensión), y que esto iba impermeabilizando y cegando el fondo del vaso de la albarrada. Al acumularse el detritus a través de varias temporadas vieron que era necesario volver a vaciar el pozo de préstamo, esto se convirtió en una actividad comunitaria. Lo que se retiraba del relleno del vaso de la albarrada se colocaba en los muros de la misma manera como se lo había hecho en su construcción, reemplazando de esta manera lo que se había erosionado por el viento y la lluvia (Marcos y Tobar, 2004; Álvarez et al. 2004).

Se han identificado albarradas de muy diversas dimensiones, habiendo algunas de tan solo ciento de $\mathrm{m}^{2}$ de extensión, mientras que las más grandes pueden llegar a tener decenas de miles de $\mathrm{m}^{2}$ de extensión. También se diferencian albarradas antiguas y modernas, en las primeras en sus muros se encuentran restos culturales asociados a sitios arqueológicos; las modernas han sido construidas durante los últimos 50 años por entidades públicas o empresas privadas. La construcción de muros de retención que se perciben claramente en los perfiles estratigráficos en las albarradas más antiguas se lo iba haciendo regando y apiso- 
nando delgadas capas de material (aproximadamente $36000 \mathrm{~cm}^{3}$ ) de relleno, que se iba compactando en una estructura laminar muy resistente (Álvarez et al. 2004; Yapa, 2013).

En la construcción de albarradas de mayor tamaño se observa el reforzamiento de los muros, para evitar la afectación por el oleaje o por la creciente de los ríos que amenazaba a los muros por el exterior. Una forma de refuerzo es colocar estacas del árbol guasango clavadas en el muro y de más de un metro en la línea donde golpea el oleaje o llega a correr el río salido de su cauce, para actuar como rompeoleaje o amortiguar la fuerza de la riada. Otras formas de refuerzo de los muros se han logrado mediante la siembra de arbustos como el muyuyo, o de árboles como el algarrobo, cascol y ébano (ESPOL, 1999).

Según el inventario del Proyecto Albarradas de la Costa Ecuatoriana (Marcos y Tobar, 2004), entre el año 2000 y 2001 se localizaron 369 estructuras hidráulicas en la PSE, de las cuales 252 son albarradas; 150 de ellas están en propiedad de organizaciones comunales. De estas estructuras, 75 se ubican en la escorrentía I que drena al Estero Salado, 196 estructuras fueron localizadas en la escorrentía II que drena al Golfo de Guayaquil, 54 fueron inventariadas en la escorrentía III que drena al Océano Pacífico, y 44 en la escorrentía IV que drena hacia el río Daule en la cuenca del Guayas, como se detalla en la Tabla 1.

Las albarradas, además de ser reservorios de agua, pueden ser vistos como parte de un patrimonio cultural arqueológico, tecnológico, cognoscitivo, ecológico y social imprescindible para el sostenimiento global de la región. Los sistemas de albarradas representan una fuente equitativa y democrática del recurso agua dulce. La mayoría de las albarradas registradas son de uso colectivo y responden a un patrón comunitario de gestión. La comunidad, ya sea la comuna o la población organizada de un recinto u otro tipo de poblado, invierte de manera colectiva sus conocimientos y su fuerza de trabajo para el mantenimiento y reproducción del sistema. Esto garantiza a su vez un acceso igualmente colectivo al recurso, es decir, un acceso horizontal y equitativo.
Dentro de un conjunto de albarradas situadas en un ámbito local, pueden establecerse relaciones de complementariedad en cuanto a su patrón de uso, algunas albarradas son destinadas exclusivamente para consumo humano (doméstico), mientras que otras pueden ser de uso principalmente productivo (agricultura y ganadería) o compartir varias funciones, cubriendo de esta manera los diferentes ámbitos de necesidad con respecto al recurso. Las albarradas destinadas al consumo doméstico, se encuentran cerradas, es decir que poseen alrededor diferentes estructuras para impedir el ingreso de animales. Se realizan trabajos de limpieza y reacondicionamiento del vaso y muro de la misma. Si la albarrada es de uso doméstico, también se hacen tareas de reparación en las empalizadas o cercos que la rodean. Las acciones pueden ser manual, en este caso las tareas se realizan manualmente por los pobladores del lugar; mecanizada, en este caso las tareas de limpieza y acondicionamiento se llevan a cabo con la utilización de maquinaria pesada, y combinada entre maquinaria pesada y trabajos manuales (Marcos y Tobar, 2004; Álvarez et al. 2004).

Los usos y valores asignados a cada una de las albarradas pueden modificarse a lo largo del ciclo de uso, así una albarrada puede considerarse cerrada y estar restringida únicamente para el consumo humano, justo después del invierno cuando está recién llena y con una buena calidad de agua. Mientras que, a la llegada del verano, debido al agotamiento de otras albarradas y a la disminución de la calidad de agua, esta puede considerarse abierta a otros tipos de usuarios y usos, ya que constituye la única fuente posible del agua para animales y para algún tipo de riego específico y local. Además, la ubicación de los pozos asociados en la parte interna de las albarradas permite un uso particular del sistema, independientemente de que sean "abiertas" como la ciénega del recinto Los Pocitos, o "cerradas" como la Poza Dulce de la comuna Sube y Baja. De esta forma, se plantea un posible uso paralelo del agua de la albarrada, "abierta" si es el caso en superficie, y "cerrada" en subsuelo mediante pozos que pueden ser usados cuando la albarrada se seca.

\begin{tabular}{c|ccccccc|c}
\hline \multirow{2}{*}{ Escorrentía } & \multicolumn{7}{c|}{ Estructura hidráulica } & \multirow{2}{*}{ Total } \\
\cline { 2 - 8 } & Albarradas & Tapes & Ciénegas & Pozas & Reservorios & S.D. & 75 \\
I & 49 & 19 & 2 & 1 & 2 & - & - & 196 \\
II & 131 & 48 & 14 & 3 & - & 1 & 54 \\
IV & 34 & 18 & - & 1 & - & - & 44 \\
Total & 38 & 2 & - & 4 & 2 & 3 & 369 \\
\hline
\end{tabular}

Tabla 1. Estructuras hidráulicas en Santa Elena. Fuente: Adaptado de Marcos y Tobar, 2004.

Table 1. Santa Elena's Hydraulic structures. Source: Modified from Marcos y Tobar, 2004. 


\section{Tapes}

Además de albarradas, otras estructuras hidráulicas de tipo ancestral relevantes en la PSE son los tapes. En algunas comunas no se diferencia entre tape y albarrada, porque sus características funcionales y el uso que de ellos realizan la población comunera y parroquial se considera como parte del sistema de albarradas. La disponibilidad de agua de las albarradas o tapes está muy cuidado en las comunas por carecer de otra fuente de agua, solamente tienen acceso a comprar agua a los tanqueros quienes pueden hacer el gasto. Además, en época de lluvia los camiones no llegan por no tener buena accesibilidad, ni buen camino.

Existen tapes en albarradas y tapes en ríos, en los primeros se excava el cauce del canal ampliándolo y profundizando y esa tierra excavada se coloca formando diques como muros de contención; en los tapes de ríos funcionan como pequeños embalses que detienen la corriente de algún nivel de los ríos con el objetivo de aprovechar el agua de invierno. Se los ubica en las partes donde el cauce del río se vuelve menos ancho para abarcar una menor área y que el tape sea de menor longitud, por lo que es mucho más fácil de construir. Sin embargo, los datos del trabajo de campo nos han enseñado que el $60 \%$ de los 87 tapes inventariados se han roto en más de una ocasión (Fajardo, 2018; Herrera, 2018; Herrera G., et al 2018; Carrión et al. 2018). Estos suelen ser destruidos por las fuertes corrientes que provocan inviernos intensos o el fenómeno El Niño que ocurre con intervalos previstos de unos siete años (Álvarez et al. 2004).

Se han presentado varios diseños de tapes, los cuales han evolucionado mediante el método prueba y error realizado por los comuneros en Manglaralto, al norte de la PSE (Carrión et al. 2017; Carrión et al. 2018). (Figura 6).

- Un primer diseño consistió en recoger rocas y sedimentos y apilarlos en los cauces del río para evitar el paso del agua. Debido a la erosión producida por el agua, esto terminaba llevándose los diques sin dejar rastro alguno.

- Un segundo diseño de los diques evidencia la colocación de 7 tubos de pozos de 10" pulgadas de diámetro distribuidos uniformemente en el área del cauce del río. Las tuberías permitían el paso del agua para que no se quede estancada en su totalidad, sin embargo, la erosión siguió actuando, pero de forma más lenta, en cuanto el nivel del río subía más de lo esperado, esto terminaba llevándose los diques sin dejar rastro alguno.

- En un tercer diseño de diques se implementa el uso de gaviones que consisten en malla metálica la
DLAGRAMA DE BLOQUE DE LOS 4 DISEÑOS DE LOS TAPES REALIZADOS POR LOS COMUNEROS DE MANGLARALTO, SANTA ELENA-ECUADOR
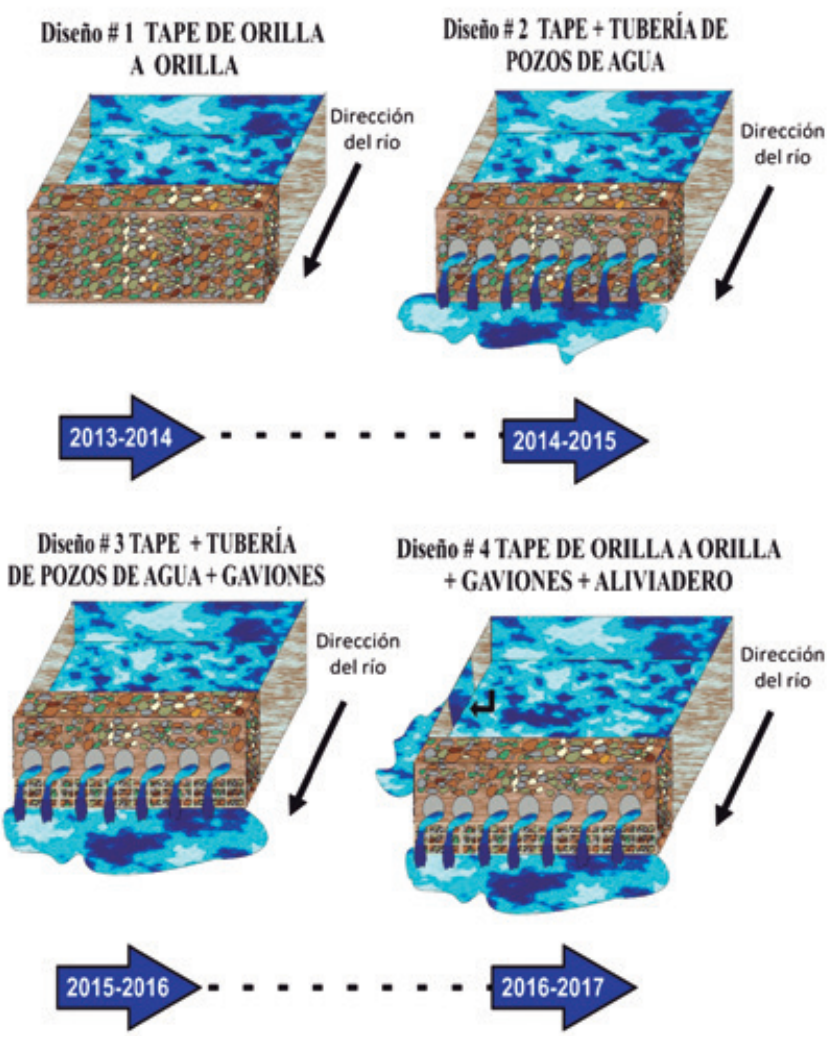

Figura 6. Evolución histórica del tape realizado en Manglaralto. Fuente: Adaptado de Carrión et al. 2018.

Figure 6. Historical evolution of the "tape" made in Manglaralto. Source: Modified from Carrión et al. 2018.

cual es rellena de rocas, estos tuvieron una medida estándar como $4 \mathrm{~m}$. de alto y $2 \mathrm{~m}$. de ancho, distribuidos a lo largo del cauce del río. Sin embargo, las rocas uniformes implementadas no brindaron el soporte esperado ya que los espacios interconectados entre las rocas permitían que la roca enmallada sufriera erosión.

- En un cuarto diseño, que aún está en funcionamiento, además de poseer tuberías y gaviones, cuenta con el uso de aliviaderos el cual es la remoción de material que almacena el río para disminuir la corriente otorgando otra dirección de la natural. Además, permite una disminución de la presión ejercida por el agua y la erosión posterior de esta.

- Por último, gracias a los estudios técnicos realizados, se pudo realizar un quinto diseño que es que actualmente está funcionando. Este tape técnico-artesanal fue construido con hormigón, pero basado y con los elementos del Diseño 4. 


\section{Siembra y cosecha de agua ( $S y C)$ en áreas rurales de Santa Elena}

Existen 22 juntas regionales de agua en la PSE encargadas de administrar y gestionar de manera comunitaria el recurso hídrico en el territorio (acuíferos, pozos y albarradas). En los últimos 30 años se han venido incorporando nuevas fuentes de agua, tales como los tanqueros, tanques elevados y el agua suministrada por tubería otorgado por empresa pública AGUAPEN. Esta empresa pública abastece de agua a parte de la población de la PSE desde 1999, principalmente áreas urbanas como Salinas y La Libertad; y actualmente a través de 10 Juntas Administradoras de Agua, Aguapen brinda el servicio a comunidades rurales.

El sistema de siembra y cosecha de agua está vinculado a la crianza de agua como un ser vivo, autónomo y capaz de reproducirse, y el conocimiento ancestral relacionado a estructuras hidráulicas en el territorio. En comunidades rurales de la PSE, la siembra de agua se genera cuando los sitios subterráneos son capaces de retener e infiltrar el agua de lluvia para recargar los mantos acuíferos, y los sitios superficiales como ríos y albarradas albergan el agua lluvia y la retienen por más tiempo, esto pretende darle un uso útil al agua Iluvia almacenada y la recarga de los acuíferos. Mientras el terreno reciba agua en una cantidad mayor a la que se evapora y a la que toman las plantas por sus raíces, el resto recargará el agua subterránea (siembra de agua). Una vez que ha aumentado la cantidad de agua (recarga), se procede a la cosecha. La cosecha de agua que se efectúa es tomar el agua y aprovecharla, esto es mediante el bombeo de pozos para obtener el agua subterránea. Para los comuneros, el agua significa siembra (agricultura), y si hay siembra hay comida y alimento, y dinero cuando se vende la cosecha. Por lo que las épocas de lluvias demarcan los ciclos de producción, así como la de acumulación y consumo de agua, convertido el sistema de siembra y cosecha de agua, en un émbolo clave para la sostenibilidad del agua y desarrollo de las comunidades rurales, demarcada las épocas de lluvia

Mediante trabajo conjunto entre el gobierno ecuatoriano, universidades y cooperación internacional han respaldado el rescate del conocimiento ancestral hidráulico mediante la rehabilitación de las albarradas y la construcción de nuevos pozos de agua para colaborar en algunos puntos estratégicos. Se han rehabilitado seis albarradas en la Península Santa Elena tales como Poza Dulce, Sube y Baja 2, El Morrillo, La Florida, Del Otro Lado, y Julio Moreno. Las tres primeras albarradas son de uso y consumo humano, las siguientes dos son de uso ganadero y la última es una albarrada de uso recreativo. En otras comunidades rurales como Manglaralto, la propia comunidad con aliados estratégicos universitarios y cooperación internacional han ido evolucionando y adaptando estos conocimientos ancestrales para responder a una demanda creciente actual, y así proveer de agua a su propia comunidad, y fortalecer sus actividades productivas como turismo y agricultura. Esto mediante la perforación de nuevos pozos de agua en el territorio para satisfacer las necesidades de la creciente población, a su vez vinculado con tapes o diques artesanales en el río Manglaralto, lo cual ha sido útil para la recarga del acuífero costero y propósitos recreativos.

\section{Casos de estudio en comunidades rurales de Santa Elena}

Comunas Sayá, Morillo, Sube y Baja, Julio Moreno (SENAGUA/AECID)

En el año 2012, la Secretaria del Agua (SENAGUA), para rescatar los saberes ancestrales para el aprovechamiento de agua mediante las albarradas, presentó un proyecto para la rehabilitación y mantenimiento de 6 albarradas en 4 comunidades de la PSE, los cuales se pueden observan en la Tabla 2 y Figura 7 (SENAGUA, 2012).

\begin{tabular}{|c|c|c|c|c|}
\hline \multirow{2}{*}{$\begin{array}{c}\text { Nombre local de la } \\
\text { Albarrada }\end{array}$} & \multirow[b]{2}{*}{ Comuna/Parroquia } & \multicolumn{2}{|c|}{ Ubicación (UTM 17S) } & \multirow{2}{*}{$\begin{array}{l}\text { Demarcación } \\
\text { Hidrográfica }\end{array}$} \\
\hline & & $\mathbf{X}$ & $\mathbf{Y}$ & \\
\hline La Florida & Sayá & 539676 & 9753375 & \multirow{6}{*}{ Guayas } \\
\hline Poza Dulce & \multirow{3}{*}{ Sube y Baja } & 560742 & 9757111 & \\
\hline Sube y Baja 2 & & 560712 & 9757908 & \\
\hline La del otro lado & & 561737 & 9757347 & \\
\hline Julio Moreno 2 & Julio Moreno & 571063 & 9758784 & \\
\hline Morrillo 1 & El Morrillo & 528041 & 9757768 & \\
\hline
\end{tabular}

Tabla 2. Listado de las albarradas rehabilitadas en la PSE. Fuente: Adaptado de SENAGUA, 2012.

Table 2. List of rehabilitated "albarradas" in the PSE. Source: Modified from SENAGUA, 2012. 


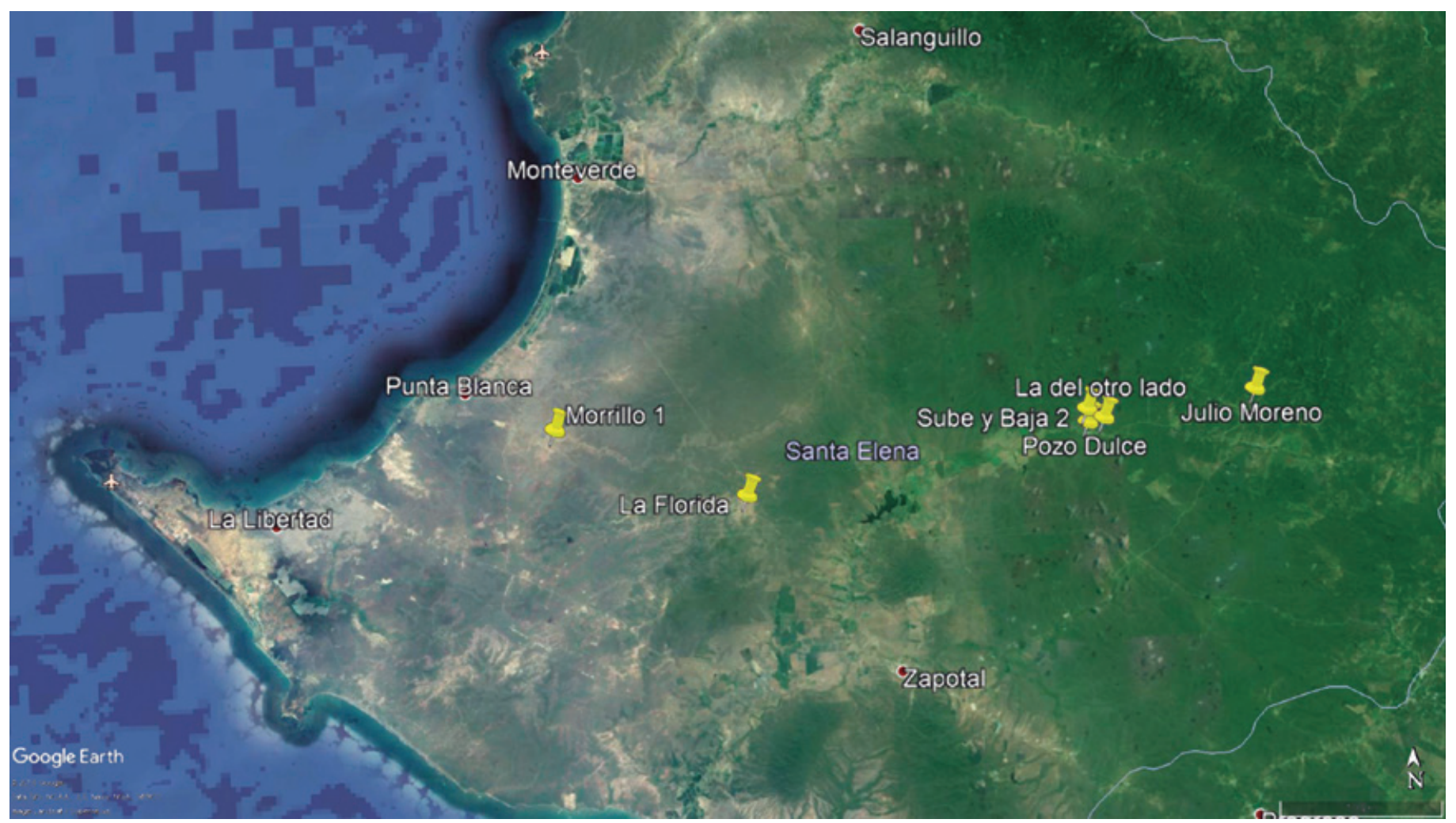

Figura 7. Ubicación satelital de las albarradas rehabilitadas en la PSE.

Figure 7. Satellite location of the rehabilitated "albarradas" in the PSE.

Para la presentación de la Propuesta de rehabilitación, una comisión designada realizó, junto con la comunidad, talleres técnicos-informativos en cada una de las comunidades (Sayá, El Morrillo, Sube y Baja y Julio Moreno), para presentar la información sobre los problemas técnicos encontrados en cada albarrada. Los problemas presentados fueron los siguientes:

- Taponamiento del canal principal de ingreso por una vía de comunicación entre recintos.

-Taponamiento agua arriba con un dique no autorizado.

- Existencia de dos roturas en la cabecera.

- Excesiva carga contaminante por parte de los usuarios agricultores y ganaderos del sector.

- Daño en las bombas que facilitan la infiltración, lo que genera una pérdida temprana de agua en superficie.

Después de analizar lo propuesto en los talleres de socialización y evaluando los problemas y los usos que le dan a las albarradas los comuneros plantearon las siguientes soluciones:

- Construcción de muelles para el adecuado paso de vehículos entre recintos.

- Limpieza del fondo de las albarradas, para que se tenga mayor capacidad de almacenamiento.
- Bloquear el ingreso del ganado y de vehículos a la perimetral de las albarradas.

- Desbroce y limpieza de la vegetación del lugar.

- Eliminación de diques que taponen la recarga natural de las albarradas.

\section{Manglaralto (JAAPMAN/CIPAT-ESPOL)}

En la PSE el abastecimiento del agua lo administra la empresa pública AGUAPEN E.P. en los tres municipios de la provincia. Sin embargo, su cobertura no abarca la parroquia Manglaralto (Figura 8), de ella se encarga la Junta Administradora de Agua Potable Regional de Manglaralto (JAAPMAN) que mediante la ayuda e investigación del Centro de Investigaciones y Proyectos Aplicados a las Ciencias de la Tierra (CIPAT-ESPOL) y del Organismo Internacional de Energía Atómica (OIEA) perforaron 12 pozos para el abastecimiento de agua que, brinda este servicio al $51 \%$ de la población de la parroquia, el resto de la población adquiere agua de pozos clandestinos, carros repartidores, canales, albarradas entre otros, asumiendo las consecuencias en su salud que esto conlleva. 


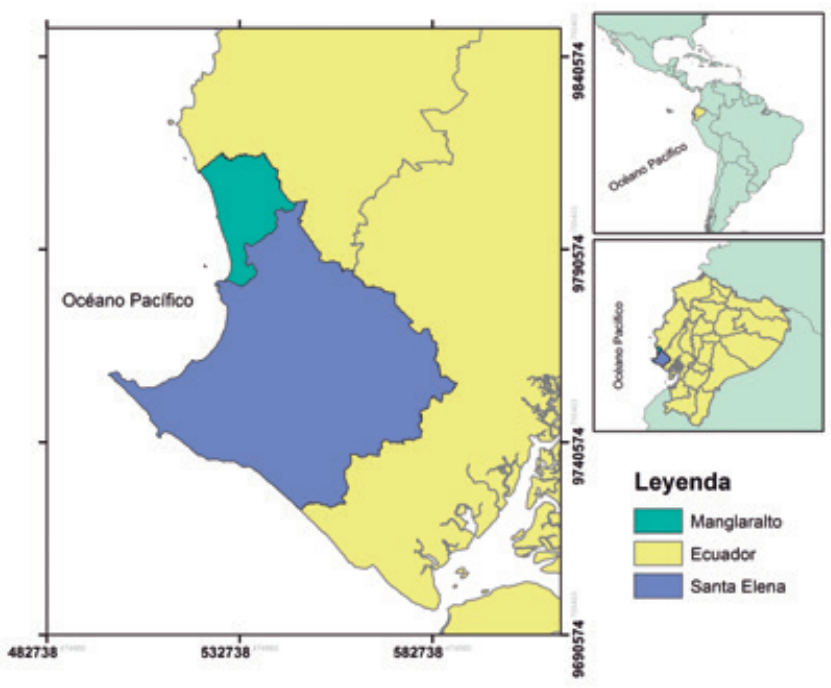

Figura 8. Ubicación de la parroquia rural Manglaralto.

Figure 8. Location of the Manglaralto rural parish.

Uno de los problemas del déficit de agua en la parroquia de Manglaralto es el bajo caudal debido a la escasez histórica de lluvias en la zona. Además, existe preocupación porque los pozos bajan cada vez más su nivel, aumentando el peligro de salinización del agua debido a su cercanía con el agua de mar (Valencia, 2017). Frente a esta problemática en la escasez de lluvias y al hecho inminente de que el recurso subterráneo se está agotando debido a la explotación de agua sin una recarga adecuada del acuífero, los tapes (diques artesanales) aparecen como una solución temporal y a la vez como una herramienta económicamente viable para poder encauzar el agua en el invierno con el fin de satisfacer las necesidades de la población durante la época de escasez. Los tapes son una denominación que los comuneros le dieron a la acumulación de rocas y sedimentos en ciertas partes del cauce del río para tratar de represar el agua o permitir que esta se acumule.

Desde el 2013 se vienen construyendo tapes para el encauzamiento de agua a lo largo del río Manglaralto para favorecer a una mejor recarga del acuífero. Las estructuras han ido evolucionando con el método de prueba y error (Figura 6), debido a la manera en cómo fueron construidos dio lugar a que fallaran durante la época invernal (Figura 9). En el año 2018, gracias a los estudios y diseños presentados en las tesis de Herrera (2018) y Fajardo, (2018), los comuneros, con asesoramiento de técnicos de la ESPOL, construyeron un tape técnico-artesanal de hormigón; es decir, ya un diseño integral que incluya las observaciones y conocimiento de profesionales y, que, a su vez, toma en consideración la experiencia de la comunidad (Figura 10).

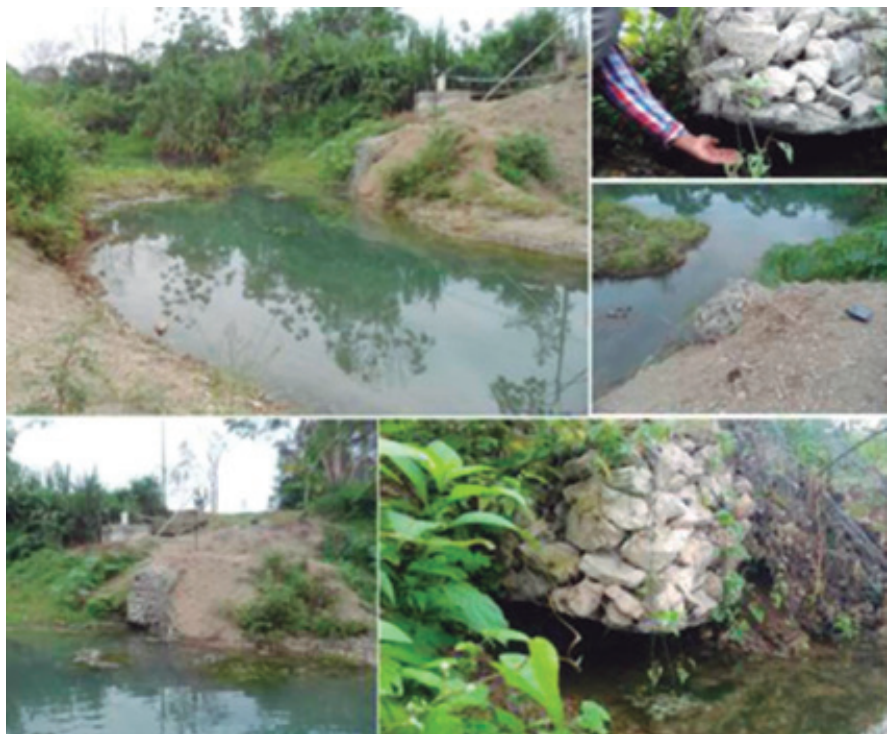

Figura 9. Falla de un tape artesanal durante la época invernal., visto desde diferentes puntos.

Figure 9. Failure of an artisanal "tape" during the winter season, seen from different views.

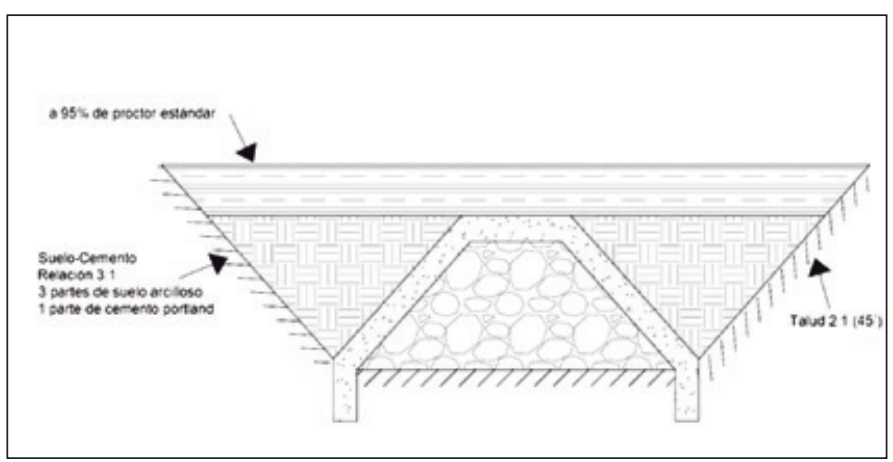

Figura 10. Vista transversal del tape técnico-artesanal. Fuente: Adaptado de Herrera, 2018.

Figure 10. Sectional view of the technical-artisanal "tape". Source: Modified from Herrera, 2018.

\section{Discusión}

Las familias del sector rural de la PSE descienden de los pobladores nativos que habitaban estas tierras desde hace 5000 años conservando sus raíces culturales. El pueblo comunero peninsular gestiona, administra y aprovecha colectivamente sus recursos hídricos con sentido comunitario y conciencia colectiva, en donde prima una lógica de cooperación social y no de lucro.

El uso de estas estructuras hidráulicas ancestrales, como son las albarradas y los tapes, les ha servido a las comunidades de la PSE para proveerse del recurso agua en épocas de escasas lluvia; además, de al punto de casi olvidarse de la no atención de la empresa pú- 
blica en estas zonas. Estas estructuras cumplen varias tareas que en corto tiempo no se logra apreciar, como son:

- Recarga de los acuíferos del sector: como en las comunas de la PSE, especialmente en Manglaralto, los acuíferos son esenciales en el diario vivir de las personas. La recarga de estos, proporciona una regular gestión del agua por parte de las Juntas de Agua de cada comunidad. En el caso de Manglaralto, gracias a las investigaciones y toma de muestras en los pozos por parte del CIPAT-ESPOL, se puede apreciar, en la Figura 11, el aumento del nivel piezométrico del agua en los acuíferos en los meses o periodos de presencia de lluvia. Cabe destacar que el nivel piezométrico presenta tres variaciones particulares: i) comúnmente entre los meses de abril y septiembre se presenta una disminución de los niveles, debido a que es época seca en Manglaralto; ii) de los meses de octubre-marzo, en concordancia con la llegada de la época de lluvia, los niveles de los pozos tienen un aumento, gracias al funcionamiento de los tapes y iii) en el mes de agosto 2013, se presenta el aumento de nivel en algunos pozos, justamente en concordancia con la reconstrucción de uno de los tapes destruidos por el invierno pasado.

- Nuevo espacio para el ecoturismo: Gracias a las albarradas y tapes, las aguas de los ríos se acumulan, con lo que, al principio se planeaba era la reserva de agua para los periodos de escasez de agua en la zona; pero poco después, se fue transformando en balnearios de agua dulce, lo que genera en el sector, un nuevo atractivo turístico. Un ejemplo de ello, se puede observar en la Figura 12 en los tapes de Manglaralto.

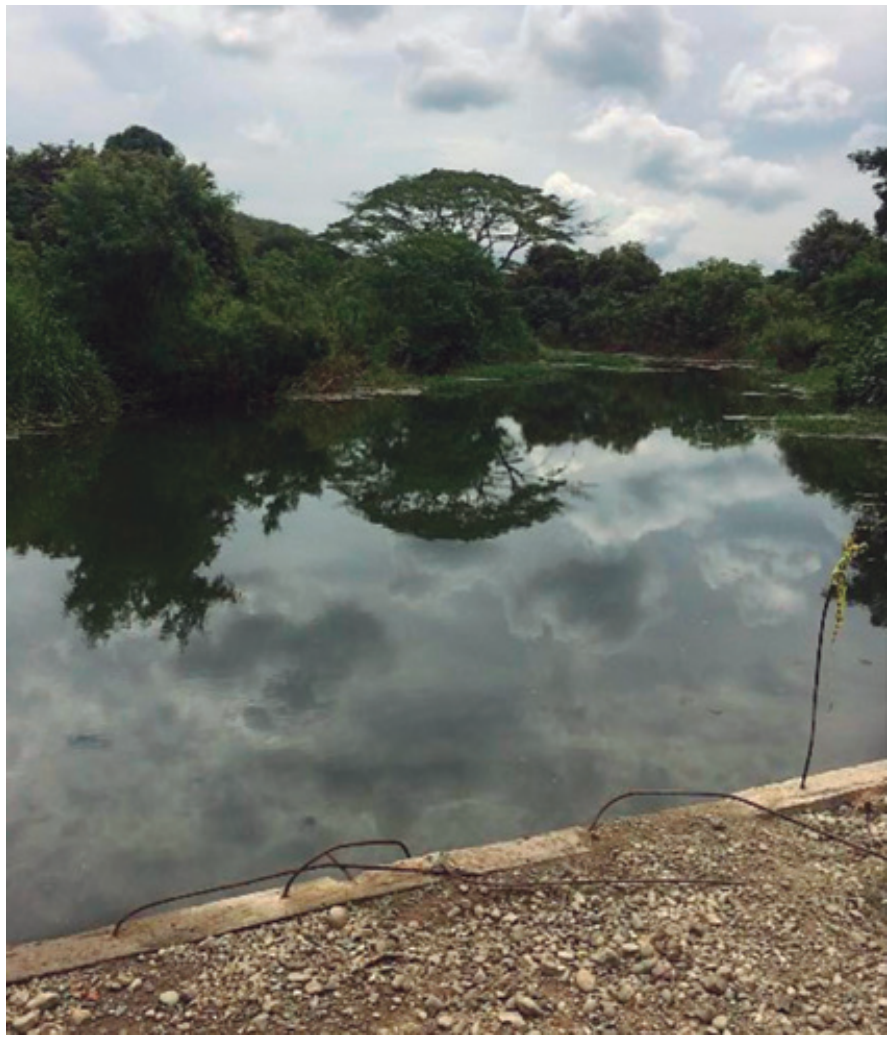

Figura 12. Tape técnico-artesanal, último realizado por la JAAPMAN. Figure 12. Technical-artisanal "tape", the last made by JAAPMAN.

- Nuevo espacio comercial: Como en tiempos ancestrales, los comuneros ahora acuden al río no solo para distraerse bañándose en los tapes, sino también pescar. Entre la variedad se encuentran camarones y peces.

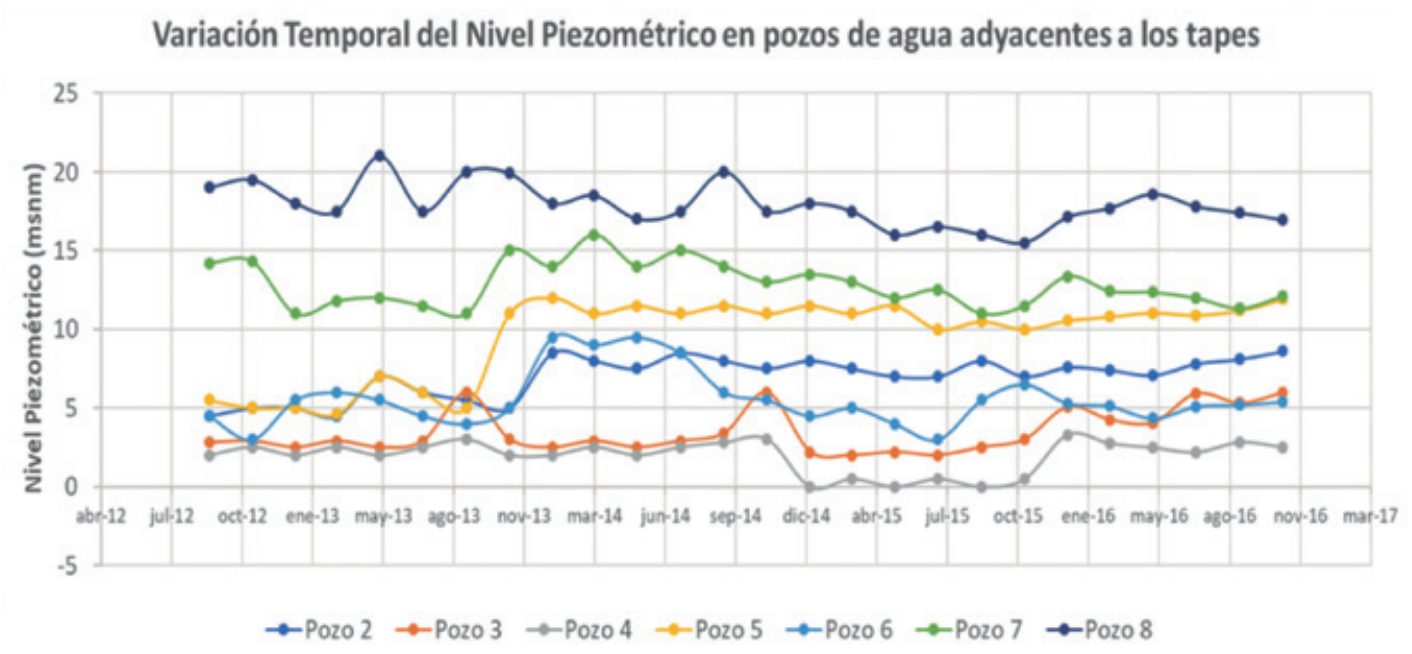

Figura 11. Variación temporal del nivel piezométrico en los pozos de la JAAPMAN.

Figure 11. Temporal variation of the groundwater level in the JAAPMAN wells. 
- Ayuda al medio ambiente: Gracias a los beneficios que trae la acumulación de agua debido a las albarradas y tapes, la comunidad se ha preocupado y ha trabajado activamente en la conservación y mantenimiento de estos. En la comunidad de Manglaralto, la ESPOL, debido a sus actividades de voluntariado y de vínculos con la sociedad, realizó junto con la comunidad talleres de socialización sobre medidas de preservación del recurso agua, como es la reforestación en zonas desérticas. El plan de reforestación dos veces al año ha permitido cuidar este nuevo elemento del ecosistema, además de brindar más espacio a la fauna local.

\section{Conclusiones}

El agua como recurso no se refiere sólo a un ámbito que compete a la colectividad, sino que es un factor dentro de un sistema de relaciones socioambientales.

El agua subterránea en la PSE muestra práctica de un sistema de siembra y cosecha de agua, que se ha convertido en émbolo clave para la sostenibilidad del agua y desarrollo de las comunidades rurales, fortaleciendo el conocimiento ancestral como la estructura de albarradas y tapes e integrándola a un conocimiento científico enfocado en preservar el recurso hídrico en el territorio.

El conocimiento ancestral ha permitido suplir en forma temporal uno de los principales problemas que tienen muchas comunas de Santa Elena, especialmente la comuna de Manglaralto, que es la escasez de agua en la temporada seca o de verano. También en Olón se realizan tapes, siguiendo la metodología aplicada en Manglaralto, y con ello se logra el aprovechamiento sostenible mediante el manejo del sistema río-acuífero. La eficacia de las albarradas y de los tapes, en lo que respecta a la recarga artificial, se evidencia en el aumento de los niveles piezométricos de los pozos adyacentes a estas estructuras hidráulicas ancestrales. Además de que les ha servido como motor ecoturístico y también como propulsor para el incremento y mayor cuidado de la flora y fauna del sector.

\section{Agradecimientos}

Este trabajo es una contribución a la Red CYTED P419RT0577 "Siembra y Cosecha del Agua en Áreas Naturales Protegidas". También agradecemos a nuestros socios estratégicos en el trabajo de campo a la JAAPMAN de Manglaralto, Santa Elena-Ecuador.

\section{Referencias}

Agudelo, R. 2005. El agua, recurso estratégico del siglo XXI. Revista Facultad Nacional de Salud Pública, 22 (1), 91-102.

Álvarez Litben, S., \& Zulaica, L. (2015). Indicadores de sustentabilidad en sistemas de albarradas: aportes metodológicos. Letras Verdes. Revista Latinoamericana de Estudios Socioambientales, 184-207.

Álvarez, S., Bazuco, M., Burmester, M., González, C., \& Escobar, P. (2004). Tomo I Comunas y comunidades con Sistemas de Albarradas Descripciones Etnográficas. Quito: Editorial Abya-Yala.

Ancajima Ojeda, R. (2015). Sistemas Hidráulicos Pre Incas e Incas. Conferencia Magistral: Tecnologías Ancestrales (págs. 1-9). Lima: Ministerio del Ambiente.

Arévalo, M. (2017). Propuesta de diseño de construcción, acondicionamiento de un pozo de agua y su incidencia en la vulnerabilidad del acuífero costero en Manglaralto., Tesis de postgrado. Escuela Superior Politécnica del Litoral (ESPOL), Facultad de Ciencias Naturales y Matemáticas (FCNM), Guayaquil, Ecuador.

Calvo-Mendieta, I., Petit, O., \& Vivien, F. (2017). Common Patrimony: A Concept to Analyze Collective Natural Resource Management. The Case of Water Management in France. Ecological Economics, 126-132. https://doi.org/10.1016/j. ecolecon.2017.02.028.

Carrión, P., Herrera, G., Cordero, G., Erazo, K., Zambrano, K. \& Limón, J. (2017). Recarga artificial de acuíferos en Santa Elena, experiencia de origen ancestral. caso Manglaralto. Almadén Proceedings 2017, 153-168.

Carrión, P., Herrera, G., Briones, J., Sánchez, C., \& Limón, J. (2018). Practical adaptations of ancestral knowledge for groundwater artificial recharge management of Manglaralto coastal aquifer, Ecuador. Sustainable Development and Planning $X, 375-386$. doi:10.2495/SDP180341.

Diario El Universo, 08/04/2012, http:// www.eluniverso. com/2012/04/08/1/1430/bosques-costeros-amenazados-deforestacion-mas-cultivos.html

Erickson, C.L. 1992. Prehistoric landscape management in the andean Highlands: raised field agriculture and its environmental impact. Popul. Environ. 3, 285-300.

Escuela Superior Pólitécnica del Litoral (ESPOL), Manejo del agua en las Costas del Ecuador, 1999, http:// www. http:// albarradas.espol.edu.ec/

Fajardo, I. \& Campoverde, J. 2018. Contribución de la geología aplicada para la mejora en el diseño de un dique en la subcuenca del rioManglaralto, provincia de Santa Elena. Tesis de grado. Escuela Superior Politécnica del Litoral (ESPOL), Facultad de Ingeniería en Ciencias de la Tierra (FICT), Guayaquil, $139 \mathrm{pp}$.

Galloway McLean, K. (2012): “Land use, climate change adaptation and indigenous peoples", en OurWorld 2.0, octubre 2012. Disponible en: http://ourworld.unu.edu/en/land-use-climate-change-adaptation-and-indigenous-peoples 
Gunderson, L., \& Holling, C. (1995). “Barriers and bridges to the renewal of ecosys-tems and institutions.", en Columbia University Press.

Herrera, G., \& Flores, D. (2011). Aspectos socioeconómicos de la gestión del agua y el turismo en las comunas Olón y Manglaralto de la provincia de Santa Elena (Ecuador). Boletín Geológico y Minero 108 (6) , 47-52.

Herrera, G. 2015. Estudio para un Modelo de Gestión de un Acuífero Costero, mediante Metodologías Participativas y Análisis Geoestadístico en el marco del Desarrollo Local. Manglaralto, Ecuador.Tesis de doctorado. Universidad Politécnica de Madrid (UPM), Departamento de Ingeniería Topográfica y Cartografía, Madrid, España, 197 pp.

Herrera, G., Carrión, P., \& Alvarado, N. (2018). Participatory Process for Local Development: Sustainability of Water Resources in Rural Communities: Case Manglaralto-Santa Elena, Ecuador. En L. F. (Ed.), Handbook of Sustainability Science and Research. World Sustainability Series (págs. 663-676). Springer, Cham.

Herrera, P. 2018. Análisis de la construcción de un dique como solución para el problema de abastecimiento de agua de la parroquia Manglaralto. Tesis de grado. Escuela Superior Politécnica del Litoral (ESPOL), Facultad de Ingeniería en Ciencias de la Tierra (FICT), Guayaquil, 143 pp.

Johns Hopkins School of Public Health. 1998. Solutions for a water-short world. Popul Rep M, 26 (1), 1-30.

Kosolapova, N., Matveeva, L., Nikitaeva, A., \& Molapisi, L. (2017). Modeling resource basis for social and economic development strategies: Water resource case. Journal of Hydrology , 438-446. https://doi.org/10.1016/j.jhydrol.2017.08.007.

Marcos, J., \&Tobar, O. (2004). La Investigación Arqueológica e Histórica de las Albarradas de la Costa. En J. Marcos (Ed.), Las Albarradas en la Costa del Ecuador: Rescate del conocimiento ancestral del manejo sostenible de la biodiversidad (págs. 31-126). Guayaquil: CEAA-ESPOL.

Melendo, J. 2017. El agua, un recurso cada vez más estratégico. Cuadernos de estrategia, 186, 71-118.

Nakashima, D. J., K. Galloway McLean, H. D. Thulstrup, A. Ramos Castillo, y J. T. Rubis (2012): Weathering Uncertainty: Traditional Knowledge for Climate Change Assessment and Adaptation. París: UNESCO/Darwin: Universidad de las Naciones Unidas. Disponible en: http://unesdoc.unesco.org/images/0021/002166/216613E.pdf

Ortloff, C.R. 1999. Urban water supply and agricultural systems in the early centuries $B C$ and $A D$ : comparison of old (Roman and Hellenistic) and new world (South American Chimu, Tiwanaku) hydraulic technologies. Seventeenth Congress of International Commission on Irrigation and Drainage: History Seminar 3, 25-36.

Paris, E., Peraza Lope, C., Masson, M., Delgado Kú, P., \& Escamilla Ojeda, B. (2018). The organization of stingless beekeeping (Meliponiculture) at Mayapán, Yucatan, Mexico. Journal of Anthropological Archaeology , 1-22. https://doi. org/10.1016/j.jaa.2018.07.004.
Pazmiño Manrique, P., Barragán, J., \& García Sanabria, J. (2018). Progress on coastal management in ecuador (2007-2017). Environmental Science \& Policy , 135-147. https://doi.org/10.1016/j.envsci.2018.09.016.

Rivadeneira N., G., \& Peralta Proaño, J. (2009). Reporte de investigación $N^{\circ} 2$. Derechos colectivos en la gestión del agua en el Ecuador. Programa de Investigación interdisciplinaria y Capacitación Interactiva sobre Gestión Local del Agua y Políticas Hídricas en la Región Andina. Cochabamba: Live Graphics s.r.l.

Saeteros, M. 2014. Estimación de la tarifa del agua de los acuíferos costeros para la gestión sostenible del recurso. Caso de estudio: Manglaralto, Santa Elena, Ecuador. Tesis de grado. Escuela Superior Politécnica del Litoral (ESPOL), Facultad de Ciencias Sociales y Humanísticas (FCSH), Guayaquil, 200 pp.

Secretaría del Agua (SENAGUA). 2012. Rehabilitación de seis (6) albarradas en el cantón Santa Elena. Informe Técnico de resultados. Guayaquil, $145 \mathrm{pp}$.

Serrano-Coronel, G., Chipana-Rivera, R., Moreno-Pérez, M., \& Roldán-Cañas, J. (2018). Study of vertical water flows contribution to the crop water consumption in suka kollus using a mixed drainage system. Agricultural Water Management , 86-94. https://doi.org/10.1016/j. agwat.2018.05.003.

Schwartz, N., y Deruyttere, A. (1996), Consulta Comunitaria, Desarrollo Sostenible y el Banco Interamericano de Desarrollo. Un marco conceptual. Banco Interamericano de Desarrollo. Departamento de Programas Sociales y DesarroIlo Sostenible. Unidad de Pueblos Indígenas y Desarrollo Comunitario. Washington. D.C.

Sixt, G., Klerkx, L., \& Griffin, T. (2018). Transitions in water harvesting practices in Jordan's rainfed agricultural systems: Systemic problems and blocking mechanisms in an emerging technological innovation system. Environmental Science \& Policy , 235-249. https://doi.org/10.1016/j.envsci.2017.08.010.

Stothert, K. (1995). Las albarradas tradicionales y el manejo de aguas en la Península de Santa Elena. Boletín del Área Cultural del Banco Central del Ecuador, 8(1), pp. 131-160.

Váldez, F. (2006). Agricultura ancestral Camellones y Albarradas. Contexto social, usos y retos del pasado y del presente. Quito: Ediciones Abya-Yala.

Valencia, J. (2017) Análisis hidrogeológico de la cuenca del río Manglaralto para la caracterización de sus sistemas acuíferos. Proyecto de grado, Escuela Superior Politécnica del Litoral (ESPOL), Ecuador, $262 \mathrm{pp}$.

Yapa, K. A. (2013). Prácticas ancestrales de crianza de agua. Una guía de campo. Estrategias para adaptarnos a la escasez de agua. Quito: Editorial Abya-Yala.

Recibido: julio 2019

Revisado: noviembre 2019

Aceptado: enero 2020

Publicado: marzo 2021 